\title{
Complete Molecular Response in Chronic Myeloid Leukemia After Six Months of Imatinib: A Single Center Experience
}

\author{
Umera Saleem $^{1}$, Talha Hafeez ${ }^{2}$, Syed Ali Raza ${ }^{2}$, Muhammad Tahir ${ }^{2}$, Fatima Khalid ${ }^{2}$, Muhammad \\ Khurrum Islam $^{2}$ \\ 1. Pathology, Nishtar Medical University \& Hospital, Multan, PAK 2. Oncology, Jinnah Hospital, Lahore, PAK
}

Corresponding author: Umera Saleem, umera_saleem@yahoo.com

\begin{abstract}
Introduction: The hallmark of chronic myeloid leukemia (CML) is the development of the fusion gene, BCRABL which has unopposed tyrosine kinase activity. The first tyrosine kinase inhibitor (TKI) imatinib is claimed to have superior efficacy and side effect profile as compared to traditional treatment options. This study was conducted to see our patients' molecular response to imatinib treatment. The objective of this study was to determine the frequency of complete molecular response in patients after six months of imatinib therapy.
\end{abstract}

Methods: A descriptive case series was designed and conducted in Oncology department, Jinnah hospital Lahore (May-November 2016). Newly diagnosed patients of CML aged between 20 and 65 years were enrolled. They were prescribed $400 \mathrm{mg}$ imatinib daily and complete molecular response was assessed after six months of treatment.

Results: Mean age was $39.76 \pm 9.072$ years. Some 66 of them were males while 69 were females. Some 40 patients (29.6\%) were found to be in complete molecular response after six months of imatinib therapy.

Conclusion: Imatinib at a dose of $400 \mathrm{mg} / \mathrm{day}$ is optimal as the primary therapy for CML.

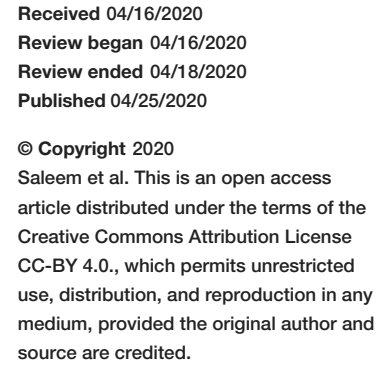

Categories: Pathology, Oncology, Hematology

Keywords: chronic myeloid leukemia, imatinib

\section{Introduction}

Chronic myeloid leukemia (CML) is a myeloproliferative neoplasm in which translocation between chromosome 9 and 22 leads to the development of a hybrid chromosome 22 called as Philadelphia chromosome. The underlying molecular defect is a fusion gene called BCR-ABL which encodes the oncoprotein BCR-ABL1 (also referred to as p210, p190, p230) with a constitutive active tyrosine kinase activity [1-2].

The annual incidence rate of CML is 0.7-1.0 per 100,000 people [3]. The natural course of the disease is triphasic: a chronic phase (CP), an accelerated phase (AP), and a blast crisis (BC). The majority of patients are diagnosed in the $\mathrm{CP}[4]$.

Tyrosine kinase inhibitor (TKI) therapy has promising response rates in CML [5]. Imatinib mesylate was the prototype drug approved by FDA in 2001. This has revolutionized the treatment of CML from control towards cure [6]. This study was conducted to document response rates in our patients to standard dose of imatinib.

\section{Materials And Methods}

A descriptive case series was conducted in the Oncology department, Jinnah Hospital, Lahore from 24th May 2016 to 23 rd November, 2016. A sample size of 135 cases was calculated with $95 \%$ confidence level, $8 \%$ margin of error, and considering expected frequency of complete molecular response as $34 \%$. Patients of both genders having age range between 20 and 65 years of CML were selected as the study population. Patients with prior treatment for CML or those having serological evidence of infection by human immunodeficiency virus were excluded.

Approval of hospital ethical review committee was taken and anonymity of data was maintained. After taking written informed consent, diagnostic and baseline tests were performed at presentation. All patients were prescribed imatinib at a dose of $400 \mathrm{mg}$ daily for six months. Molecular response was assessed after six months of treatment and monitored by FISH analysis on peripheral blood sample.

The data were analyzed using SPSS version 20. Mean and standard deviation were calculated for quantitative 


\section{Cureus}

variables such as age. Qualitative variables such as gender and complete molecular response were expressed as frequencies. Effect modifiers such as age and gender were controlled by stratification. Poststratification chi-square test was applied and $\mathrm{p}$ value $\leqslant 0.05$ was taken as significant.

\section{Results}

A total of 135 cases were recruited in the study. Mean age of the patients was $39.76 \pm 9.0$ years with an age range between 24 and 65 years. Only $7.4 \%$ were younger (<35 years). Female gender constituted $51.1 \%$ of total patients.

Splenomegaly was seen in $86 \%$ and Philadelphia positivity in $98.9 \%$. Characteristics of study population are shown in Table 1.

Sokal score of our patients was as follows: $6 \%, 30 \%$, and $64 \%$ in low risk (LR), intermediate risk (IR), and high risk (HR) category respectively.

\begin{tabular}{|c|c|c|c|}
\hline Characteristics & Baseline & Post six months & p value \\
\hline $\mathrm{Hb}$ & $11.8 \pm 3.5$ & $10.5 \pm 1.8$ & 0.0001 \\
\hline TLC & $30.73 \pm 5.38$ & $21.32 \pm 5.91$ & 0.0001 \\
\hline Platelet count & $405.5 \pm 280$ & $316.0 \pm 155.5$ & 0.0001 \\
\hline Basophils & $19.2 \pm 4.39$ & $19.2 \pm 5.55$ & 0.0001 \\
\hline Blasts & $10.41 \pm 1.68$ & $6.04 \pm 3.94$ & 0.0001 \\
\hline Philadelphia chromosome positivity & $98.9 \pm 20.68$ & $23.37 \pm 19.5$ & 0.0001 \\
\hline
\end{tabular}

TABLE 1: Characteristics of study population.

Some 40 patients (30\%) fulfilled the criteria of complete molecular response after six months of imatinib therapy. Among age groups, older patients and female gender achieved complete molecular response than young patients and male gender (Table 2).

\begin{tabular}{|c|c|c|c|}
\hline \multirow{2}{*}{ Complete molecular response } & Yes & No & p value \\
\hline & Number (percentage) & Number (percentage) & \\
\hline \multicolumn{4}{|c|}{ Overall } \\
\hline & $40(30)$ & $95 \quad(70)$ & 0.0321 \\
\hline \multicolumn{4}{|c|}{ According to age groups } \\
\hline$<35$ years & $04 \quad(40)$ & $06 \quad(60)$ & \multirow{3}{*}{0.0452} \\
\hline $35-50$ years & $19 \quad(33.3)$ & $38 \quad(66.7)$ & \\
\hline \multirow[t]{2}{*}{$>50$ years } & $17 \quad(66.7)$ & $51 \quad(75)$ & \\
\hline & \multicolumn{3}{|c|}{ According to gender } \\
\hline Male & $14(21.2)$ & 52 (78.78) & \multirow{2}{*}{0.024} \\
\hline Female & $20(29)$ & $49(71)$ & \\
\hline
\end{tabular}

TABLE 2: Distribution of complete molecular response according to age and gender.

\section{Discussion}

Chronic myeloid leukemia is a clonal disorder which leads to uncontrolled proliferation of myeloid cells. The 
disease generally has an indolent course and remains stable for years. In few patients, however, it can transform to an AP or a blast phase with a poor outcome.

The disease can manifest at any age but generally is believed to be a disease after fifth decade of life. Mean age of our patients was 39.76 years. This is similar to other studies conducted in Southeast Asia but lower than compared to Western countries such as Sweden where mean age of presentation is reported to be 60 years [7-9]. The difference could be attributed to demographic characteristics of developing countries or genetic factors.

Female gender was more common than males in our study (51.1\%). This was unusual as CML is reported to be more common in males [10].

None of the patients was asymptomatic and moderate to massive splenomegaly was seen in $86 \%$ of our patients. Our findings are comparable to a Nigerian study where $91.2 \%$ patients had splenomegaly [11].

Philadelphia chromosome is a constant feature of CML seen in more than 90\% of patients [4]. It was positive in $98.9 \%$ of our patients at diagnosis with BCR-ABL fusion gene in $100 \%$ patients.

Out of 135 patients, $6 \%$ of our patients were in LR category according to Sokal score, $30 \%$ in IR category, and $64 \%$ in HR group. These are comparable to a Pakistani study by Usman et al. which quotes 3.7\%, 27.4\%, and $67.7 \%$ respectively [12]. However the pattern reported by a study in Nigeria is different compared to the present study results (LR-40.3\%, IR-33.6\%, and HR-26.1\%) [13].

Complete molecular response was seen in $30 \%$ of our patients after six months of $400 \mathrm{mg}$ imatinib therapy (p value 0.0321 ). Our results are in concordance to a randomized CELSG phase III CML 11 “ISTAHIT” study where 34\% patients achieved complete molecular response [14]. Another phase III randomized, open-label study of daily imatinib $400 \mathrm{mg}$ versus $800 \mathrm{mg}$ in CML found that the $20 \%$ patients taking standard dose of imatinib had complete molecular response and that safety and efficacy of both doses were equal [15]. While in ELN study, the response on standard dose was 32\% [16].

The response to imatinib in $>50-65$ years age group was $66.7 \%$. This is comparable to a Swedish study where it was $79 \%[17]$.

More females (29\%) responded to imatinib than males (20\%). This difference was statistically significant. Our results are similar to those of Lin et al. [18].

\section{Conclusions}

Imatinib induces complete molecular response in CML especially in older patients and females after six months of therapy. Therefore, imatinib at a dose of $400 \mathrm{mg} /$ day should be considered as optimal primary treatment for CML.

\section{Additional Information \\ Disclosures}

Human subjects: Consent was obtained by all participants in this study. Ethics Commitee Jinnah Hospital Lahore issued approval 10/Oncoogy/2016. This is to certify that the study protocol "Complete Molecular Response in Chronic Myeloid Leukemia After Six Months of Imatinib: A Single Center Experience" has no ethical issues against it. Animal subjects: All authors have confirmed that this study did not involve animal subjects or tissue. Conflicts of interest: In compliance with the ICMJE uniform disclosure form, all authors declare the following: Payment/services info: All authors have declared that no financial support was received from any organization for the submitted work. Financial relationships: All authors have declared that they have no financial relationships at present or within the previous three years with any organizations that might have an interest in the submitted work. Other relationships: All authors have declared that there are no other relationships or activities that could appear to have influenced the submitted work.

\section{References}

1. Jain $\mathrm{P}$, Kantarjian $\mathrm{H}$, Patel KP, et al.: Impact of BCR-ABL transcript type on outcome in patients with chronic-phase CML treated with tyrosine kinase inhibitors. Blood. 2016, 127:1269-1275. 10.1182/blood2015-10-674242

2. Holyoake TL, Vetrie D: The chronic myeloid leukemia stem cell: stemming the tide of persistence . Blood. 2017, 129:1595-1606. 10.1182/blood-2016-09-696013

3. Höglund M, Sandin F, Simonsson B: Epidemiology of chronic myeloid leukaemia: an update. Ann Hematol. 2015, 94:241-247. 10.1007/s00277-015-2314-2

4. To Yeung D, Hughes TP: Chronic myeloid leukemia. Postgraduate Hematology, 7th ed. Hoffbrand AV, Higgs DR, Keeling DM, Mehta AB (ed): John Wiley \& Sons Ltd, London; 2016. 419-437. 
5. Eadie LN, Dang P, Saunders VA, et al.: The clinical significance of ABCB1 overexpression in predicting outcome of CML patients undergoing first-line imatinib treatment. Leukemia. 2017, 31:75-82. 10.1038/leu.2016.179

6. Beinortas T, Tavorienė I, Žvirblis T, Gerbutavičius R, Jurgutis M, Griškevičius L: Chronic myeloid leukemia incidence, survival and accessibility of tyrosine kinase inhibitors: a report from population-based Lithuanian haematological disease registry 2000-2013. BMC Cancer. 2016, 16:198. 10.1186/s12885-016-2238-9

7. Kuntegowdanahalli LC, Kanakasetty GB, Thanky AH, Dasappa L, Jacob LA, Mallekavu SB: Prognostic and predictive implications of Sokal, Euro and EUTOS scores in chronic myeloid leukaemia in the imatinib eraexperience from a tertiary oncology centre in Southern India. Ecancermedicalscience. 2016, 10:679. 10.3332/ecancer.2016.679

8. Mendizabal AM, Garcia-Gonzalez P, Levine PH: Regional variations in age at diagnosis and overall survival among patients with chronic myeloid leukemia from low and middle income countries. Cancer Epidemiol. 2013, 37:247-254. 10.1016/j.canep.2013.01.002

9. Höglund M, Sandin F, Hellström K, et al.: Tyrosine kinase inhibitor usage, treatment outcome, and prognostic scores in CML: report from the population-based Swedish CML registry. Blood. 2013, 122:12841292. 10.1182/blood-2013-04-495598

10. Irfan SM, Bhurgri Y: Clinico-pathological features and outcomes in chronic phase chronic myeloid leukemia patients treated with hydroxyurea. Asian Pac J Cancer Prev. 2009, 10:591-594.

11. Korubo KI, Omunakwe HE, Nwauche CA, Ejele OA: Pattern of presentation of chronic myeloid leukemia in port Harcourt Nigeria: an eight year study. Gazette Med. 2016, 4:1521494766.

12. Usman M, Syed NN, Kakepoto GN, Adil SN, Khurshid M: Chronic phase chronic myeloid leukemia: response of imatinib mesylate and significance of Sokal score, age anddisease duration in predicting the hematological and cytogenetic response. J Assoc Phys India. 2007, 55:103-107.

13. Oyekunle AA, Osho PO, Aneke JC, Salawu L, Durosinmi MA: The predictive value of the Sokal and Hasford scoring systems in chronic myeloid leukaemia in the imatinib era. J Hematol Malig. 2012, 2:25-32. 10.5430/jhm.v2n2p25

14. Petzer AL, Wolf D, Fong D, et al.: High-dose imatinib improves cytogenetic and molecular remissions in patients with pretreated Philadelphia-positive, BCR-ABL-positive chronic phase chronic myeloid leukemia: first results from the randomized CELSG phase III CML 11 “ISTAHIT" study. Haematologica. 2010, 95:908913. 10.3324/haematol.2009.013979

15. Jabbour EJ, Cortes JE, Kantarjian HM: Resistance to tyrosine kinase inhibition therapy for chronic myelogenous leukemia; a clinical perspective and emerging treatment options. Clin Lymphoma Myeloma Leuk. 2013, 13:515-529. 10.1016/j.clml.2013.03.018

16. Baccarani M, Rosti G, Castagnetti F, et al.: Comparison of imatinib $400 \mathrm{mg}$ and $800 \mathrm{mg}$ daily in the front-line treatment of high-risk, philadelphia-positive chronic myeloid leukemia: a European Leukemia Net Study. Blood. 2009, 113:4497-4504. 10.1182/blood-2008-12-191254

17. Bower H, Björkholm M, Dickman PW, Höglund M, Lambert PC, Andersson TM: Life expectancy of patients with chronic myeloid leukemia approaches the life expectancy of the general population. J Clin Oncol. 2016, 34:2851-2857. 10.1200/JCO.2015.66.2866

18. Lin HX, Sjaarda J, Dyck J, et al.: Gender and BCR-ABL transcript type are correlated with molecular response to imatinib treatment in patients with chronic myeloid leukemia. Eur J Haematol. 2016, 96:360-366. 10.1111/ejh.12597 